SCIREA Journal of Clinical Medicine

ISSN: 2706-8870

http://www.scirea.org/journal/CM

February 10, 2022

SCIREA

Volume 7, Issue 1, February 2022

https://doi.org/10.54647/cm32766

\title{
Clarifying the structure of repeated serious injuries on female rugby players
}

\begin{abstract}
Koh Sasaki ${ }^{1 *}$, Kensuke Iwabuchi ${ }^{2}$, Ichiro Watanabe ${ }^{3}$, Akihiko Nakamura ${ }^{4}$, Takumi Yamamoto $^{5}$, Keiko Asami ${ }^{6}$, Tetsuya Tsubakiha ${ }^{3}$, Mitsuyuki Nakayama $^{2}$, Haruhiko Sato ${ }^{7}$, Haruko Hirai $^{8}$, Morihiro Saito ${ }^{9}$, Zenko Miyazaki ${ }^{10}$, Takashi Katsuta ${ }^{11}$, and Ichiro Kono

${ }^{1}$ Research center for Health, Physical fitness and Sport/Nagoya University, Nagoya, Aichi 4648601, Japan.
\end{abstract}

${ }^{2}$ High performance committee, Japanese Rugby Football Union, Minato, Tokyo 1070061, Japan.

${ }^{3}$ Department of Physical Education/Tokyo City University, Setagaya, Tokyo 158-8557, Japan. ${ }^{4}$ Department of Pediatric Surgery/Nakamura Hospital, Setagaya, Tokyo 1660015, Japan. ${ }^{5}$ Department of Physical Education/National Defense Academy, Yokosuka, Kanagawa 2398686, Japan.

${ }^{6}$ Women rugby committee, Japanese Rugby Football Union, Minato, Tokyo 1070061, Japan. ${ }^{7}$ Department of Neurosurgery/Seirei Mikatahara General Hospital, Shizuoka 4338558, Japan. ${ }^{8}$ Graduete school of comprehensive human sciences/Tsukuba University, Tsukuba, Ibaraki 3058557, Japan.

${ }^{9}$ Safety management committee, Japanese Rugby Football Union, Minato, Tokyo 1070061, Japan.

${ }^{10}$ Faculty of data sciences/Rissho University, Kumagaya, Saitama 3600161, Japan.

${ }^{11}$ High Performance Sport Centre/Japan Sport Council, Minato, Tokyo 1070061, Japan. *corresponding author; sasakikoh@htc.nagoya-u.ac.jp 


\section{ABSTRACT}

The aim of this study was to grasp the injury situation of Japanese female rugby players in 2020-2021 by network analysis with psychological condition under COVID19 (June 1-30, 2021). The number of respondents was 302 . $60 \%$ reported serious injuries. The parts were ankle, knee, shoulder, head, etc. Symptoms are ligament / bone / muscle damage or concussion. The caused plays were tackle/tackled, running with no physical contact, etc. There were 39 head injuries. Some ones played while continuing long-term treatment such as knees and ankles. Approximate $40 \%$ of players injured once were injured twice again, and approximate $40 \%$ of players injured twice were injured a third time. $30 \%$ of all respondents had some chronic symptoms. Network analysis revealed a structure with multiple chronic symptoms (head, shoulders, knees, ankles), a structure of multiple parts of injuries in a single play, and a structure in which the same parts were repeatedly injured in a year. Some players suffered concussions after knee injuries. It suggested the possibility that the physical safety management skills to protect the head might be inferior due to insufficient recovery of knee function as a negative injury chain structure.

Keywords: rugby union, female injury, network structure

\section{Introduction}

Rugby Union is an interpersonal competitive sport that involves physical contact, and evidence-based longitudinal studies have been conducted on the injuries ${ }^{1-3}$. A 14-year longitudinal study of young male rugby players has revealed that those with less years of experience often suffered serious injuries ${ }^{4}$.

Studies on the injury of female rugby players have been undertaken ${ }^{5-7}$, but there are a few detailed descriptive approaches. The physique of female rugby players has been expanding, and the playing opportunities have been increasing 8 . In the decade leading up to the 2021 Olympic Games in Tokyo, the female rugby players' population in Japan doubled ${ }^{9}$. The female rugby players' population in France was reported to grow $40 \%$ each year in the early $2010 \mathrm{~s}^{10}$. Shelborne ${ }^{11}$ suggested that female players had relatively high frequency of knee injuries, and knee surgery took time to recover. In recent years, serious injuries in female players have also 
been reported. A study reported that female rugby players' recovery period from concussion was longer than that of male players ${ }^{10}$. It would be an urgent issue from the standpoint of prevention to elucidate the occurrence of serious injuries including concussion in female rugby players.

From the perspective of injury prevention, the relationship between chronic symptoms and evidence of repeated injuries might be important. It would be a viewpoint to understand the injury as not a single phenomenon but a network with the player's previous symptoms and the situations where the injuries are repeated in a short period of time. Network analysis is useful for understanding the chain structure of serious injuries ${ }^{12}$.

Network analysis could elucidate the cooperative structure among the factors in the organization. This approach has been developed in many practical science areas to understand the human behaviors. Biological approaches include discussions on the causes of sports injuries $^{4,5,13}$. Some core factors in physiological parameters during exercise-induced fatigue were clarified and discussed with the risk management for human health ${ }^{13}$.

The purpose of this study was to clarify the injury situation (including serious injuries such as concussion) of female rugby players in Japan at 2020-2021 by network analysis. Subjects were female players over 16 years old registered with the Japanese Rugby Football Union, who understands the contents of the research and agrees to participate in it of free will by anonymous questionnaire method.

\section{Results}

302 players responded (23\% of all 1,313 registered female players on Japanese Rugby Football Union over the age of 16: average age $=19$ years old: the $65 \%$ have 4 years or more of rugby experience; the $21 \%$ have 10 hours or more of weekly practice time; the $22 \%$ have a representative or academy experience) (Figure 1). 


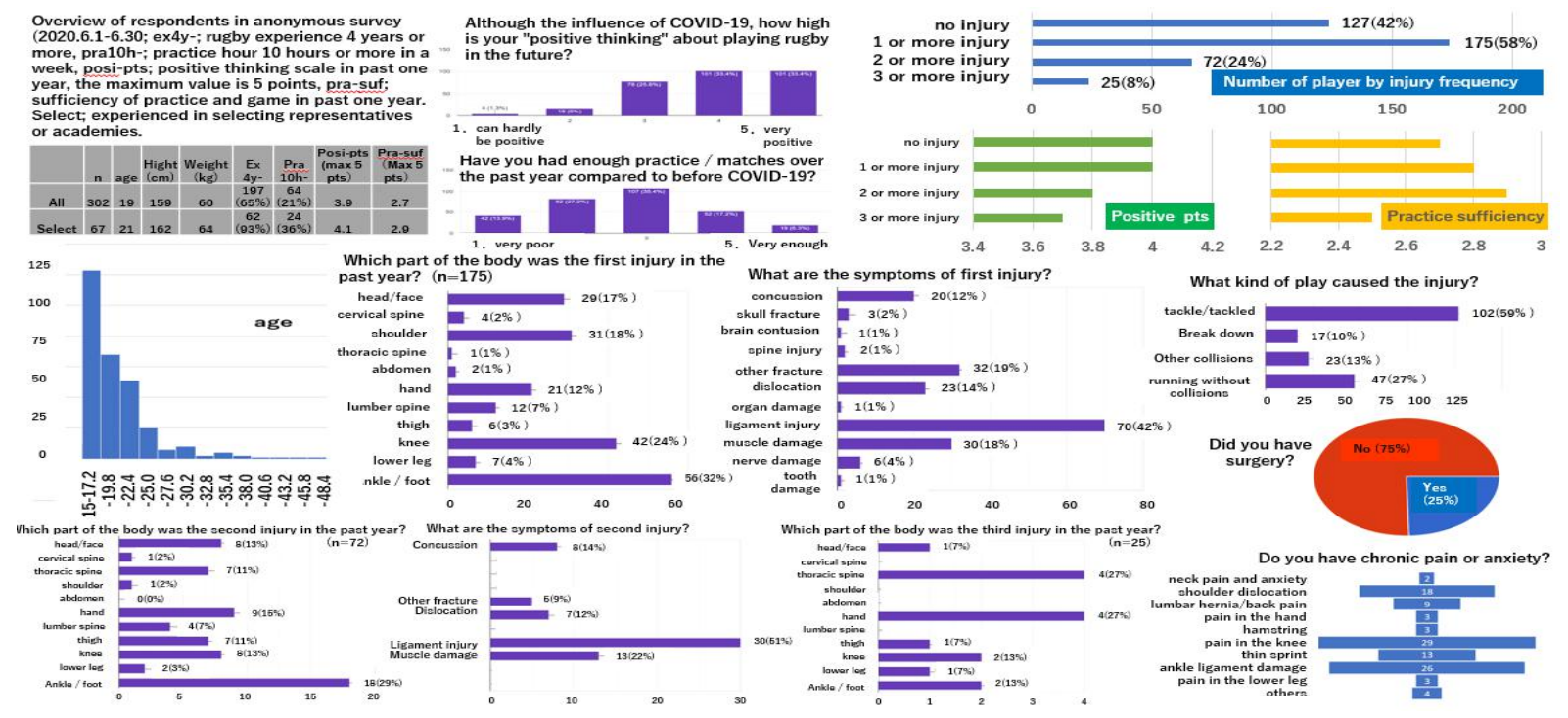

Figure 1. Overview of respondents in anonymous survey (2021.6.1-6.30; ex4y-; rugby experience 4 years or more, pra10h-; practice hour 10 hours or more in a week, posi-pts; positive thinking scale in past one year, the maximum value is 5 points, pra-suf; sufficiency of practice and game in past one year. Select; experienced in selecting representatives or academies.

The 93\% have "positive thinking" points about playing rugby in future of some influence of COVID-19 (scale 3,4, and 5), and $7 \%$ answered that they could not be positive thinking. The $40 \%$ answered that they had not been able to achieve sufficient condition of the practice and the game compared to the before COVID-19 days. 175 players (about $60 \%$ of all) reported injuries more than once in the past year (body parts; ankles/feet (32\%): knees (24\%): shoulder/clavicle (18\%): head/face (17\%); symptoms; ligament injury (41\%): fracture/bone injury (19\%): muscle injury (18\%): dislocation (14\%): concussion (12\%)). The causes of play were tackle/tackled (59\%), running without collision (27\%), other collisions (13\%), and breakdown (10\%). $25 \%$ required surgery.

The players injured twice or more in the past year were $72(42 \% \because 72 / 172)$. The injured body parts were ankles, hands, head, shoulders, thighs, and knees, which were more extensive than the first time. The second symptoms were most often ligament injury (similar to the first), followed by muscle injury, concussion, dislocation, and fracture. Concussion was $14 \%$. The causes of the play were tackle/tackled (59\%), running without collisions (20\%), other collisions (21\%), breakdown (8\%). The $10 \%$ required surgery.

The players injured third or more in the past year were $35 \%(\because 25 / 72)$. As the values of $42 \%$ from the 1 st to the 2 nd $(72 / 172)$, and $35 \%$ from the 2 nd to the 3 rd $(25 / 72)$, the rate of repeated 
injuries was approximately $40 \%$. The parts and symptoms were ankles, hands, shoulders (ligament injury, dislocation, fractures, etc.), head (concussion), thighs, and knees. The 5\% required surgery.

The $39 \%$ of players (119/302) answered they had chronic pain or anxiety. The most common parts were knees $(24 \%)$, ankles $(22 \%)$, and shoulders (15\%). The ratio on all respondents was $10 \%$ for knees, $9 \%$ for ankles, and $6 \%$ for shoulders.

\begin{tabular}{|c|c|c|c|c|c|c|c|c|c|c|c|c|c|}
\hline part & symptoms & $n$ & $\begin{array}{l}\text { caused } \\
\text { play }\end{array}$ & surgery & $\begin{array}{l}\text { avg. days to } \\
\text { return to play }\end{array}$ & hight & weight & age & ex4y- & $\begin{array}{l}\text { Pra } \\
10 h-\end{array}$ & posi-pts & pra-suf & Select \\
\hline \multirow{3}{*}{$\begin{array}{c}\text { head/ } \\
\text { face }\end{array}$} & concussion & 21 & $t k \mid=15$ & 0 & $30(1 \sim 90)$ & 161 & 62 & 19 & 13 & $4 / 21$ & 3.9 & 3 & $6 / 21$ \\
\hline & fracture & 6 & $t k k^{\prime}=4$ & 4 & $65(14 \sim 200)$ & 158 & 57 & 17 & 5 & $4 / 6$ & 4.2 & 2.5 & $2 / 6$ \\
\hline & muscle damage & 2 & $t \mathrm{kl}=2$ & 0 & $5(3 \sim 7)$ & 159 & 62 & 17 & 5 & $2 / 2$ & 4.5 & 3.5 & $0 / 2$ \\
\hline spine & Cervical spine injury & 5 & $\mathrm{tkl}=2$ & 2 & $177(7-360)$ & 158 & 58 & 23 & 3 & $2 / 4$ & 3.5 & 2.5 & $1 / 5$ \\
\hline \multirow[b]{4}{*}{ shoulder } & dislocation & 17 & $t k k^{\prime}=15$ & 9 & $132(10 \sim 240)$ & 160 & 62 & 19 & 16 & $9 / 17$ & 4.1 & 2.4 & $3 / 17$ \\
\hline & muscle damage & 4 & $|k|=4$ & 0 & $25(14 \sim 30)$ & 157 & 62 & 16 & 2 & $2 / 4$ & 3.5 & 3.5 & $0 / 4$ \\
\hline & fracture & 4 & $|k|=2$ & 2 & $90(30 \sim 210)$ & 158 & 58 & 18 & 3 & $3 / 4$ & 4 & 2.5 & $0 / 4$ \\
\hline & ligament injury & 3 & $|k|=3$ & 0 & $45(30 \sim 60)$ & 158 & 61 & 19 & 2 & $0 / 3$ & 4.0 & 3 & $0 / 3$ \\
\hline abdomen & organ damage & 2 & $\mathrm{tkl}=1$ & 1 & $60(\mathrm{NA}-60)$ & 159 & 61 & 22 & 2 & 1 & 4 & 2.5 & $1 / 2$ \\
\hline \multirow{2}{*}{$\begin{array}{l}\text { lumber } \\
\text { spine }\end{array}$} & spine injury & 4 & $\begin{array}{c}\mathrm{tkl}=3 \\
\text { run=2 }\end{array}$ & 0 & $56(10-150)$ & 164 & 64 & 21 & 4 & 2 & 4 & 3.75 & $3 / 4$ \\
\hline & fracture / nerve injury & 3 & $\begin{aligned} \mathrm{tkl}=2 \\
\mathrm{run}=1 \\
\end{aligned}$ & 0 & $155(45-360)$ & 157 & 60 & 19 & 3 & 0 & 4 & 2.3 & $0 / 3$ \\
\hline $\begin{array}{c}\begin{array}{c}\text { Thoracic } \\
\text { spine }\end{array} \\
\end{array}$ & fracture & 1 & $\mathrm{tkl}=1$ & 0 & 14 & 162 & 57 & 17 & 1 & 1 & 4 & 2 & $1 / 1$ \\
\hline \multirow{4}{*}{ hand } & fracture & 8 & $t \mathrm{k} \mid=4$ & 4 & $41(14-60)$ & 158 & 57 & 18 & 6 & 1 & 3.9 & 3.1 & $0 / 8$ \\
\hline & ligament injury & 2 & $t k \mid=1$ & 0 & $37(14-60)$ & 150 & 50 & 33 & 0 & 0 & 3.5 & 2 & $0 / 2$ \\
\hline & muscle damage & 1 & & 0 & 3 & 158 & 60 & 16 & 1 & 1 & 4 & 4 & $0 / 1$ \\
\hline & dislocation & 1 & $\mathrm{tk} \mid=1$ & 0 & UT & 156 & 58 & 18 & 1 & 0 & 5 & 2 & $1 / 1$ \\
\hline thigh & muscle damage & 4 & run $=4$ & 0 & $82(28-180)$ & 166 & 64 & 21 & 2 & 2 & 4.3 & 4 & $1 / 4$ \\
\hline \multirow{4}{*}{ knee } & ligament injury & 21 & $\begin{array}{l}\text { tk }=12 \\
\text { run }=11\end{array}$ & 15 & $178(30 \sim 360)$ & 161 & 66 & 20 & 15 & $8 / 21$ & 4 & 2.57 & $11 / 21$ \\
\hline & muscle damage & 4 & $\begin{array}{c}\mathrm{tk} \mid=3 \\
\mathrm{run}=1\end{array}$ & 1 & $83(14 \sim 270)$ & 160 & 58 & 17 & 4 & $1 / 4$ & 3.5 & 3 & $1 / 4$ \\
\hline & fracture & 3 & $\begin{array}{c}\mathrm{t} \mathrm{k} \mid=2 \\
\mathrm{run}=1\end{array}$ & 0 & $75(60 \sim 90)$ & 157 & 63 & 22 & 2 & $2 / 3$ & 3 & 1.7 & $1 / 3$ \\
\hline & dislocation & 2 & $\begin{array}{c}\mathrm{tk}=1 \\
\text { run }=1\end{array}$ & 0 & 90 & 158 & 55 & 18 & 1 & $1 / 1$ & 4 & 2 & 0 \\
\hline Jower leg & muscle damage & 4 & run $=3$ & 0 & $62(7-120)$ & 163 & 65 & 18 & 3 & 2 & 4.8 & 3.3 & $2 / 4$ \\
\hline lower leg & ligament injury & 2 & run $=2$ & 1 & $180(60-300)$ & 158 & 58 & 21 & 2 & 2 & 4 & 2.5 & $2 / 2$ \\
\hline & ligament injury & 32 & $\begin{array}{l}\mathrm{tkl}=16 \\
\mathrm{run}=8\end{array}$ & 1 & $48(1-360)$ & 158 & 60 & 18 & 19 & 12 & 3.9 & 2.8 & $7 / 32$ \\
\hline ankle / & muscle damage & 5 & $\begin{array}{r}\mathrm{tkl}=3 \\
\text { run }=1\end{array}$ & 0 & $53(7-180)$ & 155 & 58 & 18 & 4 & 1 & 4.2 & 3.2 & $0 / 5$ \\
\hline foot & & & $\mathrm{tk} \mathrm{l}=1$ & & & & & & & & & & \\
\hline & fracture & 4 & run $=3$ & 1 & $187(14-180)$ & 162 & 60 & 20 & 3 & 0 & 4 & 3 & $2 / 4$ \\
\hline & nerve injury & 1 & $\mathrm{tk} \mid=1$ & 1 & UT_730 & 158 & 64 & 17 & 1 & 0 & 3 & 3 & $1 / 1$ \\
\hline & dislocation & 1 & $\mathrm{tk} \mathrm{l}=1$ & 0 & 90 & 167 & 67 & 16 & 1 & 0 & 4 & 2 & $0 / 1$ \\
\hline
\end{tabular}

Table 1 showed average days to recovery from the first injury. The average days to return to play were 30 days from concussion, 65 days from head/face fractures, and 177 days from cervical spine injury. The other parts for long recovery periods were, ankle (ligaments, nerve, fractures), knee (ligament, fractures), lumber spine, shoulders (dislocation). 
Theadrace,cencussion

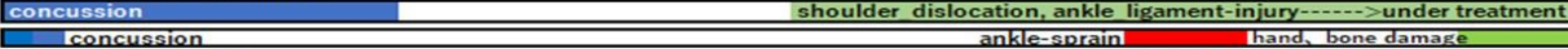

concussion ankle-sprain (recuvery;nut ciear)

cencussion

concussion 1 concussion

concleg on loncussion $\begin{aligned} & \text { con } \\ & \text { lumbar. nerve damage. }\end{aligned}$

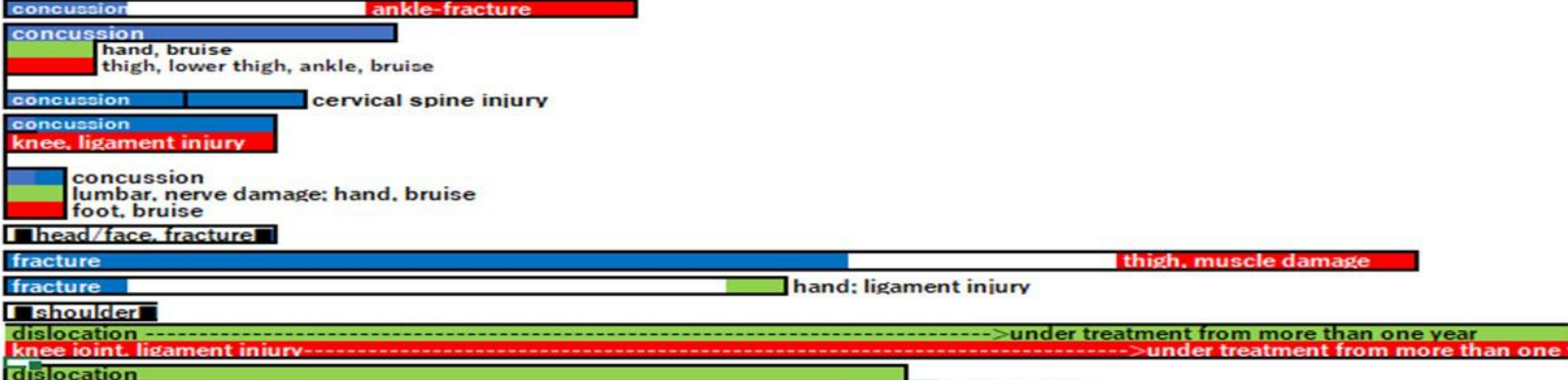

Chishocation —unkle: spraion

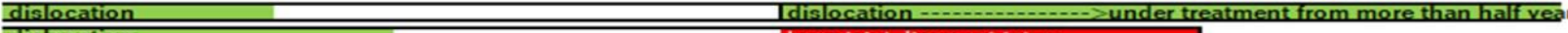
dislocation Lnee ioint. ligament iniurv Lhand; nerve damage-> under treatment

\begin{tabular}{l} 
dislocation \\
lumber, nerve damage \\
\hline igament injury ankle. sprai
\end{tabular}

Dogament injury
knee ieint. ligamentinilry

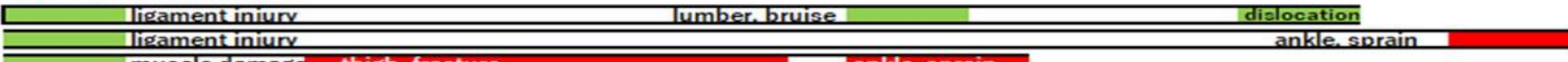
muscle damage thich. fracture

fracture nerve damage

muscle damage knee liegm int injury thigh: muscle damage

fracture ligament iniur

fracture

$\square$ hascle damage

dislocation knee fracture

nlumber?

fracture cuncussion

nervedamage anklesprain a lower thioh:muscledarnage

Thish

muscledamage muscle damage

muscle damage

Thneer

$\frac{\text { ligament iniurv, }}{\text { repeated injury before recovery ligament iniury }}$

liøament iniury "the other injury before recovery ankle, ligament iniury

lifament iniurv

ligament iniur

ligament iniurv

cuncussion

Iifament injur ligament iniurv-...-...ligament injur ligament iniurv-

nerve damage

fracture

Dower leg/ Achilles tenden

muscle-tendon damas

miracle-tendon dage and ankle ligament injury

Tankle 7 foot

Tigamen iniury Theracic spine: damage

ligament iniurv cervical spine inji hand: ligament iniury

fracture hancbruise knee: bruise

fracture 78 weeks ade hand: fracture

fracture 26 weeks agd TowerTeg/ Achilles tendon damage

muscledamage

muscledamage Imuscle damage

mercle damage cuncussion

ligament iniury

lower led: fracture

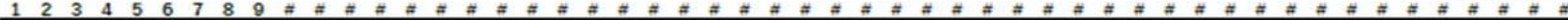

Figure. 2 The number of weeks required to recover from twice iniury or more in past one year: 2020-2021.

(A connection of two or three lines means the occurrence of simultaneous iniuries)
head/face/neck
upper body(shoulder/brest/lumber/hand) lower body/thigh//knee/lower leg/ankle/foot) 
Figure 2 showed the injuries repeated in one year in chronological order. In some cases, injuries were repeated without a sufficient recovery period, and in some cases, multiple serious injuries suffered at one time, and the recovery took a long time.

Although sufficient period to recover from a head injury must be needed, some respondents answered that they had repeated concussion or neck injuries after concussion in a short period. Various cases were answered, such as players who have been treating their shoulders and knees, and players who have injured shoulders and other parts for a long period. Some players have prolonged knee treatment. Cases have also been reported in which the knee and other areas were injured again before sufficient recovery of knee treatment.

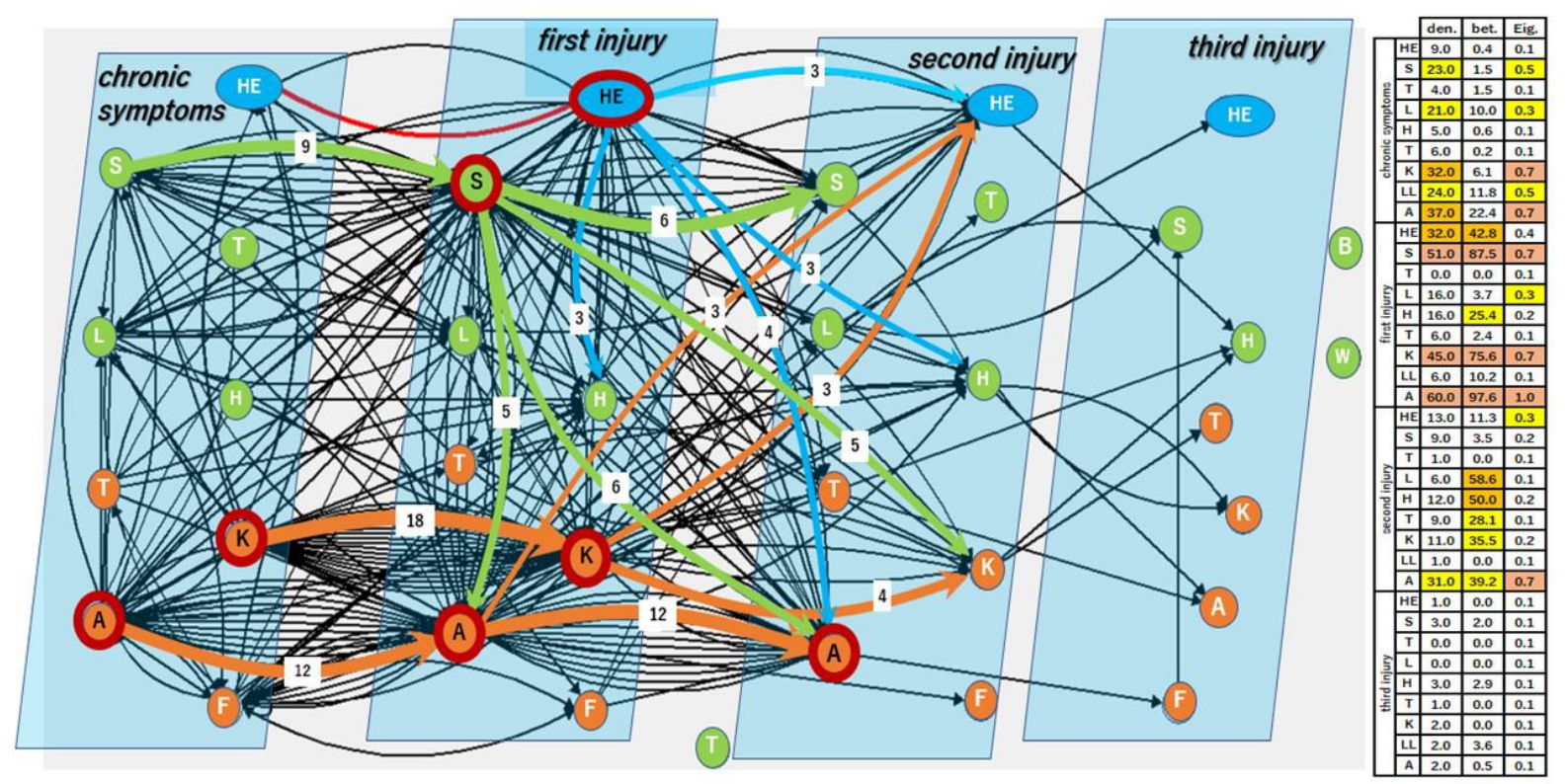

Figure 3. Network structure from chronic symptoms to $1^{\text {st }}, 2^{\text {nd }}$, and 3rd injury of Japanese women rugby players in 2020-2021 and the network centrality values (HE; head/face, S; shoulder, T; thoracic vertebra, L; lumbar vertebra, H; hand, T; thigh, K; knee, A; ankle, F; foot, den.; density centrality, bet.; betweenness centrality, eig.; eigenvector centrality, Top 3rd, 4th to 6th, 7th to 9th)

The Network analysis clarified the chain structure of the repeated injuries from chronic symptoms (Figure 3, left graph). The black arrows showed every connection of the injuries, and the thick colored arrows showed the structure of the strong connection of 3 or more ones. Red circles were added to the part where there were many injury connections. It could be understood that the knees, ankles, and shoulders were repeatedly injured by female rugby players with chronic symptoms up to the second time. In addition, this network graph showed the structure with multiple parts in chronic symptom and in each injury stage $\left(1^{\text {st }}, 2^{\text {nd }}\right.$, and $\left.3^{\text {rd }}\right)$. There were repeated head injuries, or head injuries after knee or ankle injuries.

Network centrality analysis was executed to clarify the core functions in the repeated injury network (Figure 3, right table). In this study, betweenness centrality, density centrality, and 
eigenvector centrality were used. The results showed that the knee and ankle (chronic symptoms), head, shoulder, knee, ankle (first injury), and ankle (second injury) were suggested to be the central functions in the female rugby injuries by the comparatively higher values of the three centralities.
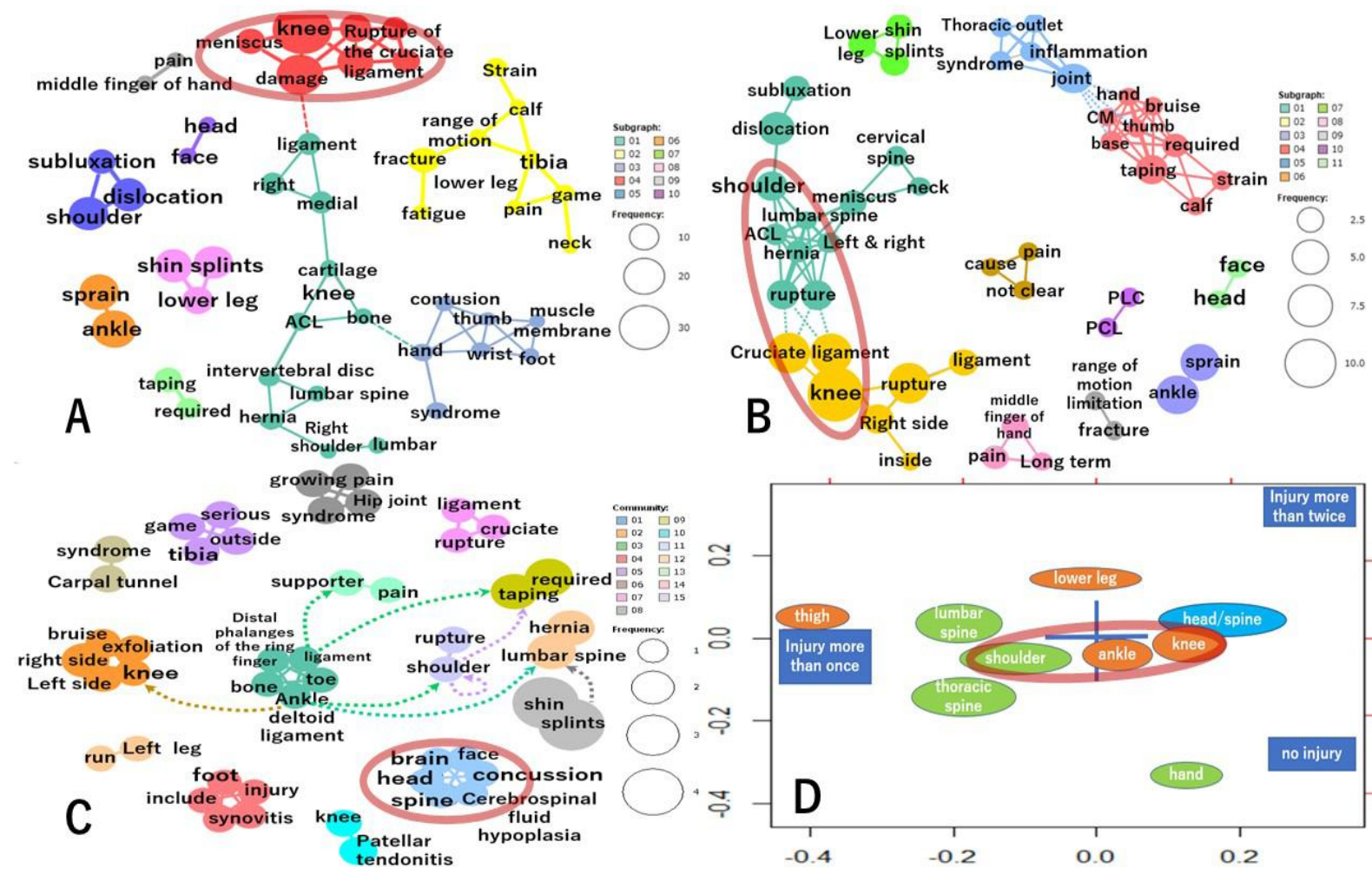

Figure 4 Co-occurrence network of chronic symptoms, pain and anxiety (descriptive analysis, A; overall, $\mathrm{B}$; no injury, C; twice or more injury) and Correspondence analysis showing the injury part of body on similarity and uniqueness among "more than once", "more than twice" and "no injury (D).

We draw a co-occurrence network diagram to see the connection of the terms reported by players for chronic symptoms (Figure 4). By this method, it would be possible to understand some chain structure with symptoms, anxiety, actual pain in multiple chronic symptoms. Chronic symptoms of the knee were high in the whole data group (A) and the no injury group (B). In a detailed view of these groups, multiple chains of chronic symptoms, with knee, lumber, shoulder, and hand. In the injury more than twice, there might have higher anxiety of head, spine, and concussion (C). Furthermore, we conducted a correspondence analysis for the detailed evidence of the chronic symptoms among "the injured more than once", "more than twice", and "no injured" as a dummy value (D) ${ }^{14,15}$. This centering resonance analysis could allow us to grasp the similarities and uniqueness within a specific group. To maximize the relationship between row and column items, correspondence analysis sorts both the rows and 
columns to identify the relationships between them. In the axial contribution ratio, the accumulated ratio on the second axis was $100 \%(73.07 \%, 100.00 \%)$, suggesting that the data was adequately represented. The common similarities parts for multiple injuries were shoulder, knee, ankle. Comparatively specific part for injury more than once was thigh (mainly hamstring injury ), and part for injury more than twice was head/spine (concussion).

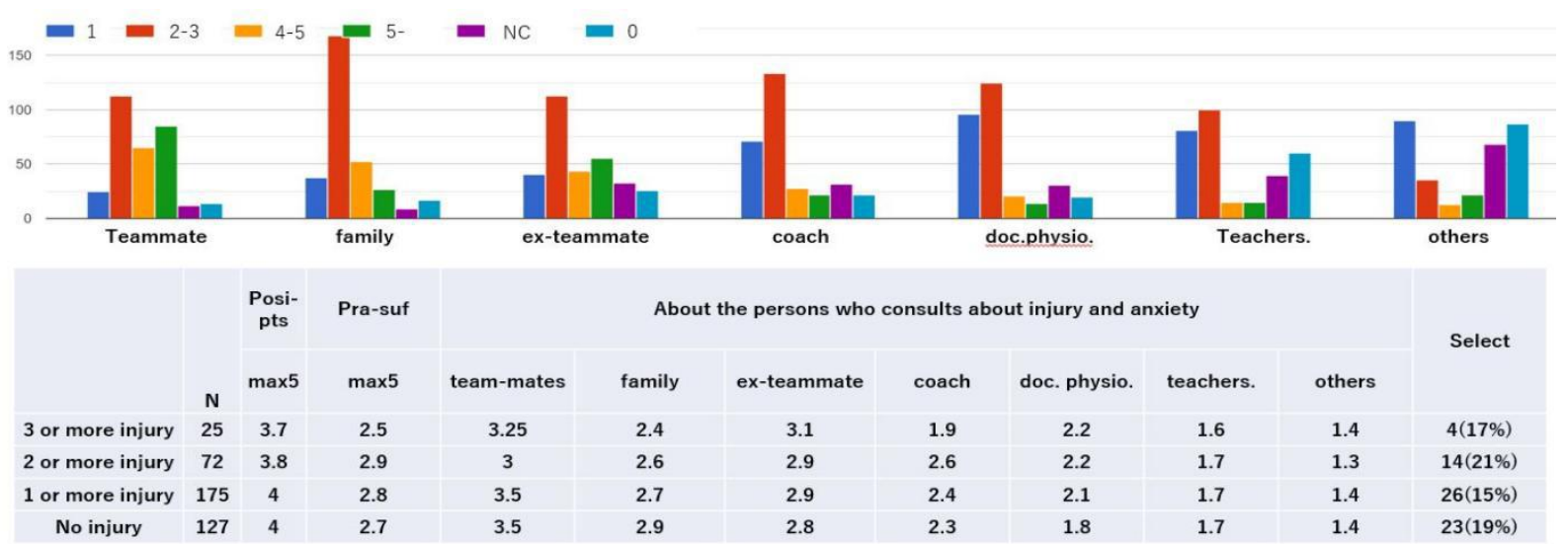

Figure 5. the numbers of persons who consults about injury and anxiety (doc. tor.; doctor or physio-therapist, teachers.; teachers or friend in workplace)

Figure 5 showed the numbers of persons who consults about injury or anxiety. There was no significant difference with the number of injuries.

\section{Discussion}

$7 \%$ of respondents answered they could not be positive thinking under the influence of COVID-19. However, Consideration for this $7 \%$ of female players would be required. Even those who answered positive may always be upset by something (serious injury or increased anxiety). Intra-team communication that leads positively rather than arousing anxiety would be required.

There were a total of 39 head and neck injuries (head 35: neck 4). It seemed that some players have returned to play from concussion without sufficient recovery period. Another study reported that only $11 \%$ players return from concussion in the recommended recovery schedule by International Federation ${ }^{16}$. It should be noted that players suffered the third times of injuries in a year and the third was a concussion. Another fact that three of ten players suffered concussion after knee injury might have a negative injury chain structure in which the physical 
skills (technique, speed) to protect head would be inferior due to insufficient recovery of knee function.

Some recent studies concerned with head safety management could be helpful. Introducing a rule that makes the tackle height below the chest might reduce the impact on the head and face ${ }^{17}$. However, players who do not have the correct skills such as avoiding "a dangerous posture with the head lowered (bent neck)" and "a posture in which the head is caught between the opponent's body and the ground and fall down" would have higher head impact ${ }^{18}$. It would be important not to down the head too much when tackling. It may be a comprehensive body defense skill that can be supported by sufficient muscle strength in the knees and lower body. In addition, there is a survey result that the correct refereeing for dangerous tackles was $59 \%$ in a game $^{19}$. In the elite rugby, both of males' and females' weight have stopped being increased, but in female league rugby, more than 14 head impact collisions per game (total) and dangerous situations are always lurking ${ }^{20}$. Rugby players with history of concussions are more than twice as likely to suffer muscle and skeletal injuries in the lower limbs ${ }^{21}$. Does concussion have a negative effect on the exertion of safety skills? Studies promoting visual information processing or reaction behavior training ${ }^{22}$ to avoid head collisions in tackles, and shortening the reaction time on open skills (decision making system) ${ }^{23}$ might also be helpful. A specific approach of developing recognition ability like vision training effects for young female athletes would be also attracting attention ${ }^{24}$.

In an injury study in Australian football, one of another rugby codes, females have higher hand, ankle and knee injuries ratios ${ }^{25}$. Shoulder injuries were the third most common part in females after ankles and knees. Among upper body injuries, organ damages have begun to be reported in recent years. As play becomes more intense, skills and trainings to protect the chest and abdomen are required. It has been reported that trained female rugby players have thicker rectus abdominis muscle mass than non-athletic women ${ }^{7}$. Knee and ankle injuries while running (with no physical contact) are relatively common in female players. The most common part of this survey was the ankle. Some players were playing with long-term treatment (Figure 3).

Co-occurring network analysis in the chronic symptoms suggested to have some relations to the injury more than once as seen in figure 3 and 4 . The chronic symptoms might need to be improved for the prevention of other serious injury throughout the body. Approximately $40 \%$ 
of Japanese female rugby players (16 years old or more) were repeatedly injured in a year. Same time, approximately $40 \%$ of players answered to have some chronic illness symptoms. In order to lower these values, it might be effective not to see the injury as a single phenomenon, but to see it as a network structure that mutually supports the other parts. In order to make up for injured and weakened part of body, some other parts would be necessary to support. If the recovery is not sufficient, the other parts will be burdened. These collaborative functions could work with both positive and negative. Furthermore, if there is psycho-social anxiety such as COVID 19, it seems essential to build a sound social relationship ${ }^{26,27}$. It would be important to have a network of multiple counselors, including teammates in the club, family, coaches, doctors and physio-therapist (Figure 5). It is necessary to create a team/organization that does not make players who suffer from multiple injuries, anxiety and loneliness.

\section{Methods}

\section{Study design and participants.}

This study was in collaboration with the JRFU Safety Management Committee. The team manager replied by e-mail if he/she read the research request and accepts the research cooperation. They then delivered the web survey to female players over the age of 16 . Players who received the research URL and responded (sent) it.

The research items were under bellow;

- positive thinking points about playing rugby in the future under COVID19 influence (Maximum 5 points)?

- sufficiency of practice and game in past one year (Maximum 5 points).

- Injury symptoms, parts, caused play, surgery, average days to return to play in the past year.

- The above contents for multiple injuries, days elapsed since the previous injury.

- Age, height, weight, rugby experience years, practice time per week, chronic symptoms and anxiety.

- About the persons who consults about injury and anxiety 
The injuries in this study were operationally defined as serious ones of more than a week to recovery after careful discussions with several doctors familiar with rugby injuries.

All procedures used in this study were approved by the Ethics Committee of the Research Center for Health, Physical Fitness and Sports, Nagoya University (21-01; 2021.5.10). Informed consent method; Subjects were informed in the preface of the questionnaire about the purpose of the study, anonymous survey, and protection of human rights and personal information. Subjects had no disadvantage even if they do not agree the study. Subjects were able to stop participating (sending) even during and after the survey. Subjects were able to refuse to answer questions that they did not want to answer or questions that you feel psychologically burdened. Subjects confirmed to agree on the answer page. Minors over the age of 16 were able to reject the study in public documents at the discretion of their parent or guardian. all methods were carried out in accordance with relevant guidelines and regulations. Above informed consent was obtained from all participants and, no parent or legal guardian rejected this study.

\section{Network Analysis}

The chain structures of injuries repeated twice or third times were analyzed as a network from chronic symptoms. In order to clarify the central function in the network, the centrality analysis was carried out. In this study, betweenness centrality, density centrality, and eigenvector centrality were used by " $\mathrm{R}$ " program. Co-occurrence network diagram was executed to see the connection of terms about symptoms by "kh-coder" program. By this method, it was available to show the chain structure with symptoms, anxiety, actual pain, etc. when there are multiple chronic symptoms. Furthermore, we conducted a correspondence analysis for the detailed evidence of the chronic symptoms among "the injured more than once", "more than twice", and "no injured" as a dummy value by "R" program[12, 2] (Suzuki, 2009: Sasaki et al., 2017). This centering resonance analysis could allow us to grasp the similarities and uniqueness within a specific group.

\section{Acknowledgements}

This study was partly supported by JSPS KAKENHI grant Number 19K11549(2019-2021). 


\section{Author contributions statement}

K.S., K.I., I.W., and A.N. conceived the study. T.Y., K.A., T.T, M.S., and Z.M. led data collection. K.S., H.S., H.H. and M.N. performed data analysis. K.S., T.K., and I.K. led preparation of the manuscript with all authors contributing to writing and editing.

\section{References}

[1] Fuller, C.W., Brooks, J.H., \& Kemp, S.P. Spinal injuries in professional rugby union: a prospective cohort study. Clinical Journal of Sport Medicine. 17(1), 10-16, doi: 10.1097/JSM.0b013e31802e9c28 (2007).

[2] Silver, J.R. The impact of the 21st century on rugby injuries. Spinal Cord. 40(11), 552559. https://doi.org/10.1038/sj.sc.3101349 (2002)

[3] Quarrie, K., Gianotti, S., \& Murphy, I. Injury Risk in New Zealand Rugby Union: A Nationwide Study of Injury Insurance Claims from 2005 to 2017. Sports Medicine. 50, 415-428, https://doi.org/10.1007/s40279-019-01176-9 (2020).

[4] Sasaki et al. Clarifying the structure of serious head and spine injury in youth Rugby $\begin{array}{lllll}\text { Union } & \text { players. }\end{array}$ https://doi.org/10.1371/journal.pone.0235035 (2020).

[5] Sasaki, K., Watanabe, I., Yamamoto, T., Yamashita, S., Tanaka, A., and Okuwaki, T. An empirical study of Japanese women's rugby injury 2016. Japanese Journal of Rugby Science. 28(1), 56-60 (2017a).

[6] Manning, K.Y. et al. Longitudinal changes of brain microstructure and function in nonconcussed female rugby players. Neurology. 95 (4), e402-412, https://doi.org/10.1212/WNL.0000000000009821 (2020).

[7] Abuín-Porras, B. et al. Comparison of the Abdominal Wall Muscle Thickness in Female Rugby Players Versus Non-Athletic Women: A Cross-Sectional Study. Medicina. 56(1), 1-9, https://doi.org/10.3390/medicina56010008 (2020).

[8] Tucker, R., Raftery M, Kemp S, et al. Risk factors for head injury events in professional rugby union: a video analysis of 464 head injury events to inform proposed injury prevention strategies. British Journal of Sports Medicine. 51, 1152-7, http://dx.doi.org/10.1136/bjsports-2017-097895 (2017).

[9] Japanese Rugby Football Union, 2020 Team registrations report. (2020).

[10] Chermann, J.F., et al., Return to Rugby After Brain Concussion: A Prospective Study in 35 High Level Rugby Players. Asian Journal of sports medicine. 5(4), e24042 doi: 10.5812 /asjsm.24042 (2014).

[11] Shelborne, K.D. et al. Posterior Tibial Slope in Patients Undergoing Anterior Cruciate Ligament Reconstruction With Patellar Tendon Autograft: Analysis of Subsequent ACL 
Graft Tear or Contralateral ACL Tear. The American Journal of Sports Medicine. 49(3), 620-625, https://doi.org/10.1177/0363546520982241 (2020).

[12] Iverson, G.L., Network Analysis and Precision Rehabilitation for the Post-concussion Syndrome. Frontiers in Neurology, 10, 489, https://doi.org/10.3389/fneur.2019.00489 (2019).

[13] Pereira, V. H., Gama, M.C.T., Sousa, F.A.B., Lewis, T.G., Gobatto, C.A., \& ManchadoGobatto, F.B. Complex network models reveal correlations among network metrics, exercise intensity and role of body changes in the fatigue process. Scientific Report. 5, 10489 https://doi.org/10.1038/srep10489 (2015).

[14] Suzuki, T. Network Analysis.2nd.ed. Tokyo (JPN): Kyouritsu Shuppan (2017).

[15] Sasaki, K., Yamamoto, T., Miyao, M., Katsuta, T., and Kono, I. Network centrality analysis to determine the tactical leader of a sports team. International Journal of Performance Analysis in Sport, 17(6), 822-831, https://doi.org/10.1080/24748668.2017.1402283 (2017b).

[16] Kearney, P.E., and See, J., Misunderstandings of concussion within a youth rugby population. Journal of Science and Medicine in Sport, 20(11), 981-985, https://doi.org/10.1016/i.jsams.2017.04.019 (2017).

[17] Tierney, G.J., Richter, C., Denvir, K., Simms, C.K., Could lowering the tackle height in rugby union reduce ball carrier inertial head kinematics? Journal of Biomechanics. 72(27), 29-36, https://doi.org/10.1016/i.jbiomech.2018.02.023 (2018).

[18] Davidow, D., Quarrie, K., Viljoen, W., Burger, N., Tackle technique of rugby union players during head impact tackles compared to injury free tackles. Journal of Science and Medicine in Sport,21(10), 1025-1031, https://doi.org/10.1016/i.jsams.2018.04.003 (2018).

[19] Brown, J.C. et al. Non-sanctioning of illegal tackles in South African youth community rugby, Journal of Science and Medicine in Sport. 21(6), 631-634, https://doi.org/10.1016/i.jsams.2017.10.016 (2018).

[20] King, D.A., et al., Head impact exposure from match participation in women's rugby league over one season of domestic competition. Journal of Science and Medicine in Sport. 21(2), 139-146, https://doi.org/10.1016/j.jsams.2017.10.026 (2018).

[21] Hunzinger, K.J., Costantini, K.M., BuzSwank, C., Buckly, T.A. Diagnosed concussion is associated with increased risk for lower extremity injury in community rugby players. Journal of science and medicine in sport. 24(4), 368-372, https://doi.org/10.1016/i.jsams.2020.10.013 (2021).

[22] Pfaff, L.M., Michael, E., and Cinelli, M.E. The effects of sport specific training of rugby players on avoidance behaviors during a head-on collision course with an approaching person. Human Movement Science. 62, 105-115, https://doi.org/10.1016/j.humov.2018.09.010 (2018).

[23] Formenti, D., Trecroci, A., Duca, M., Cavaggioni, L., D’Angelo1, F., Passi, A., Longo, S., and Alberti, G. Differences in inhibitory control and motor fitness in children practicing 
open and closed skill sports. Scientific report. 11, 4033, https://doi.org/10.1038/s41598$\underline{021-82698-z}$ (2021).

[24] Formenti, D. et al. Perceptual vision training in non-sport-specific context: effect on performance skills and cognition in young females. Scientific report. 9, 18671, https://doi.org/10.1038/s41598-019-55252-1 (2019).

[25] Gill, S.D. et al. Gender differences in female and male Australian Football injuries - A prospective observational study of emergency department presentations. Journal of Science and Medicine in Sport. 24(7), 670-676, https://doi.org/10.1016/i.jsams.2021.02.011 (2021).

[26] Russell, J.D., Neil, E.L., Victor G., Carrión, V.G., and Weems, C.F. The Network Structure of Posttraumatic Stress Symptoms in Children and Adolescents Exposed to Disasters. Journal of the American Academy of Child and Adolescent Psychiatry. 56(8), 669-677, https://doi.org/10.1016/i.jaac.2017.05.021 (2017).

[27] Legarreta, A.D. et al. The role of family and personal psychiatric history in post concussion syndrome following sport-related concussion: a story of compounding risk. Journal of Neurosurg Pediatr. 22, 238-243, https://doi.org/10.3171/2018.3.PEDS1850 (2018). 